\title{
Gamificação para o Ensino de Computação na Educação Básica
}

\author{
Michel Girotto Brum ${ }^{1,2}$, Marcia E. J. Kniphoff da Cruz', \\ ${ }^{1}$ Departamento de Computação - Curso de Licenciatura em Computação - \\ Universidade de Santa Cruz do Sul (UNISC) - Santa Cruz do Sul - RS - Brasil \\ ${ }^{2}$ Escola de Educação Básica Educar-se - Universidade de Santa Cruz do Sul (UNISC) - \\ Santa Cruz do sul - RS - Brasil \\ $\{$ michelgb, mcruz\}@unisc.br
}

\begin{abstract}
Resumo. O ensino de Computação no Brasil vem sendo incentivado com atividades pontuais, mas necessita de fomento para sua consolidação. Para contribuir com essa proposta este relato de experiência apresenta resultados de atividades realizadas em disciplina facultativa de Robótica, em escola de educação básica. Considerando que a Robótica possibilita a introdução de conteúdos da Computação e que os estudantes são nativos digitais, empregouse a gamificação que consiste em utilizar os princípios de game design à metodologia de ensino. Os resultados apresentaram melhora significativa no aprendizado do conteúdo trabalhado na disciplina e ampliação de habilidades sociais.
\end{abstract}

\begin{abstract}
The teaching of Computing in Brazil has been stimulated with specific activities, but it needs to be encouraged for its consolidation. In order to contribute to this proposal, this experience report presents results of activities carried out in an optional discipline of Robotics in a basic education school. Considering that Robotics allows the introduction of content of Computing and that the students are digital natives, the game was applied that consists of applying the principles of game design to the methodology of teaching. The results showed a significant improvement in the learning of the content worked in the discipline and expansion of social skills.
\end{abstract}

\section{Nativos Digitais e o cenário educacional}

A difusão das Tecnologias Digitais - TDs, da rede global de computadores e a web, criaram uma singularidade no tempo. As TDs se tornaram onipresentes na vida das crianças e adolescentes. $O$ intenso fluxo de informações transformou a forma como a nova geração pensa e processa informações. A partir destas constatações, Prensky (2001), denomina "Nativos Digitais", aqueles que já nasceram em meio às TDs e reforça que possuem uma linguagem própria, e diferente dos "Imigrantes Digitais" que tiveram de se apropriar das TDs mais tarde.

Os Nativos Digitais nascem em meio aos computadores, celulares e a interatividade da web. São dinâmicos, ágeis, multitarefas. Conseguem jogar on-line em grupo, conversar, comunicar-se simultaneamente, navegar na internet e esse dinamismo passou a ser uma característica básica para o mundo de um nativo. Crescem em meio à um grande fluxo de informações, recebem e processam todas as diferentes informações 
simultânea e paralelamente. Preferem o hipertexto (linguagem usada na web) ao texto linear. Os Imigrantes Digitais, por sua vez, preferem o meio analógico (como assistir uma telenovela) ao digital (como assistir conteúdo por streaming ou interativo), tem dificuldades em lidar com o ambiente virtual, preferindo meios físicos. Esta descontinuidade coloca de um lado Nativos e de outro Imigrantes. Para Prensky (2001), o único e maior problema que a educação enfrenta hoje é que os nossos professores Imigrantes Digitais, que usam uma linguagem ultrapassada (da era pré-digital), estão lutando para ensinar uma população que fala uma linguagem totalmente nova. Esta diferença entre as linguagens cria um afastamento entre Nativos e Imigrantes, afetando diretamente o processo educacional.

Prensky (2001) afirma que os alunos mudaram radicalmente, não são os mesmos para os quais o atual sistema educacional foi criado. O problema principal está no fato dos professores imigrantes usarem metodologias de ensino que funcionaram no passado. Em muitas situações desconsideram o ambiente em que os nativos vivem, repleto de conexões, velocidade e dinamismo.

O cenário educacional em alguns contextos, dentre os quais cita-se o Brasil, demoram muito a se modificar e a atingir patamares satisfatórios tanto no que diz respeito aos conteúdos tradicionais, quanto no ensino de novos conteúdos imprescindíveis de serem abordados na escola. Um conteúdo novo e necessário é a Computação que em países bem-sucedidos financeiramente e que apresentam elevados índices nos rankings internacionais de educação, tem inserido regularmente, o ensino de Computação na escola. Na Inglaterra e Austrália (Brenner, 2015) o ensino de Computação inicia aos cinco anos de idade, na França aos seis (Collas, 2016). Os Estados Unidos possuem diretrizes muito bem definidas para o currículo K12, sobre o ensino de Computação a partir da Educação Infantil. (CSTeacher, 2016). A Alemanha foca no ensino de computação e elaborou currículo específico da área para o Ensino Médio (Schmundt, 2013). Índia, Israel, Nova Zelândia, Coréia do Sul, entre outros países, já adotaram mudanças e desenvolveram currículos nacionais de TI.

\section{O ensino de computação no Brasil}

Experiências que envolvem o ensino de computação no Brasil têm ampliado, entretanto necessitam de expansão, regularidade e efetividade nos currículos escolares. Em comparação aos países citados, o Brasil está muito aquém do mínimo desejável quanto ao ensino de Computação na educação básica.

As dificuldades são observadas também, no ensino superior. Publicações científicas apontam que existem grandes dificuldades do ensino da programação nos cursos de ensino superior, conforme citado por Barbosa (2011) e Correia (2015). Esses estudos, ainda, apontam dados alarmantes sobre a evasão dos cursos de Computação; o assunto tem se tornado pauta de encontros nacionais, segundo Massa (2015). Os problemas referentes podem ser equalizados com a introdução de estudos de Ciência da Computação na Educação Básica, através do desenvolvimento do Pensamento Computacional, de lógica para programação e introdução a robótica nos currículos regulares das escolas. Outro aspecto a ser incentivado são os cursos de licenciatura em computação que formam professores para atuar na área.

Segundo Andrade et al (2013), o Pensamento Computacional se utiliza de atividades que introduzem os conceitos de coleta, análise e representação de dados, 
decomposição de problemas, simulação, automação, algoritmos, paralelismo e abstração, sem o uso de computadores. Em Ciência da Computação essas habilidades são básicas para o desenvolvimento posterior de algoritmos e programação. Poucas escolas já estão incorporando o ensino de Computação nas suas rotinas diárias. A necessidade de oportunizar o desenvolvimento do Pensamento Computacional aos estudantes da Educação Básica está relacionada ao grau de complexidade dos problemas enfrentados no cotidiano. Ribeiro (2013), afirma que, noções matemáticas trabalhadas nas séries iniciais já foram conhecimentos apenas de intelectuais em séculos passados, contudo, hoje a programação de computadores está se tornando essencial.

Códigos de programação são partes integrantes de muitos dos recursos cotidianos, mas poucos tem o conhecimento para elaborá-los, o que justifica a necessidade emergente de repensar o currículo da Educação Básica do Brasil e atualizá-lo. É importante lembrar, segundo Ribeiro (2013), que o pensamento lógico-matemático difere do Pensamento Computacional; o raciocínio computacional utiliza a lógica como uma ferramenta no processo de resolução de problemas. Significa decompor os problemas em partes menores, para que possam ser resolvidos e combinados em função do resultado final, tornando o processo todo muito mais complexo que a simples tomada de decisão. Muitas escolas ainda consideram o ensino de informática apenas como a necessidade de dominar o uso de softwares e não como uma forma de desenvolver habilidades necessárias, cada vez mais cedo, na sociedade. Essa necessidade justifica a mobilização de incansáveis esforços para popularizar a Computação na Educação Básica.

Este trabalho defende a proposta de que a metodologia ao empregar a gamificação para ensino da Computação na Educação Básica, através da robótica, oportuniza benefícios significativos para o aprendizado. Portanto, são apresentados alguns dos elementos presentes em jogos que possuem potencial para serem explorados e incorporados à metodologia de ensino.

\section{Gamificação, o design de games e a mecânica de jogo}

A gamificação tem por princípios aplicar aspectos do design de games, ao processo de ensino aprendizagem, procurando reduzir as diferenças entre os nativos digitais e o sistema de ensino tradicional. Para isso, se faz necessário encontrar quais elementos da mecânica dos games são responsáveis por atrair, envolver e incentivar os jogadores. Uma pesquisa realizada pelo Grupo de Qualidade de Software (GQS) - Instituto Nacional para Convergência Digital (INCoD) - Departamento de Informática e Estatística (INE) Universidade Federal de Santa Catarina (UFSC) buscou estatísticas com relação à preferência dos jogos por parte dos estudantes de computação, e mostrou que mais de $53 \%$ dos jogadores tem preferência por jogos de ação e aventura e Role-Playing game RPG (Battistella, 2015). Outro dado relevante faz referência ao modo de interação entre os jogadores: embora o mais usado seja o singleplayer (41\%), 40\% dos alunos têm preferência pelo modo de interação multiplayer. Destes, $23 \%$ dos jogadores preferem modos multiplayers competitivos, os quais os jogadores competem entre si, e $17 \%$ multiplayers cooperativo, os quais os jogadores colaboram entre si.

Jogos multiplayer online como Conter-Strike são ícones de ambientes imersivos e estão associados à aprendizagem ativa de diversas habilidades. Uma pesquisa conduzida com 40 pessoas com idades superior ou igual a dezesseis anos mostrou que aqueles que jogaram ao menos oito horas por semana Conter Strike, apresentaram até duas vezes e 
meia melhores habilidades multitarefas do que os demais. Para medir esta capacidade foi utilizado um software desenvolvido pelo exército norte-americano. A melhora foi atribuída ao ambiente imersivo e cenário realístico (MATTAR, 2010, p.118).

Os elementos que tornam os jogos digitais tão atrativos baseiam-se em dois pilares: o desafio e a recompensa. O desafio é representado pelas ações apresentadas durante o jogo. O jogo representa algo da realidade subjetiva. Jogos são objetivamente irreais e não recriam fisicamente as situações que representam, embora sejam subjetivamente reais para o jogador (Crawford, 1982). No ambiente imersivo do jogo Counter-Strike: Global Offensive (CS:GO) os jogadores escolhem um time: Terroristas (que tem por finalidade implantar a bomba em um ponto específico do mapa ou eliminar todos os contra terroristas) ou Contra Terroristas (que em por objetivo impedir que os terroristas implantem a bomba ou eliminar todos os terroristas). As regras e o objetivo do jogo são claros. Ao ingressar em um time ou "clã" formado por cinco componentes, os integrantes podem comunicar-se por voz durante o jogo. A comunicação é extremamente importante para que o time consiga discutir, planejar e executar ações em grupo rapidamente, pois a vitória depende, na maior parte, da habilidade de trabalho em equipe e organização do time, o que torna o jogo competitivo entre times, mas altamente colaborativo, dentro do time. Além disso, o tempo máximo de cada partida é de dois minutos, o que exige do time muita organização, agilidade e cooperação.

Já a recompensa é um resultado de seu empenho e evolução no jogo. Quanto mais praticar e melhorar seu desempenho maior será sua recompensa. A forma utilizada para representar o grau de expertise do jogador em um determinado game pode variar de jogo para jogo. Nos jogos de ação em primeira pessoa predomina o sistema de patentes, em que, conforme o usuário aprimora sua habilidade, ganha experiência (ou “ $x p$ ”, na linguagem na dos jogos). Ao ingressar no CS:GO o jogador não possui patentes e somente após ganhar dez partidas competitivas receberá a primeira (de acordo com uma avaliação de habilidade do jogador durante os primeiros jogos, realizada pelo próprio software). São ao todo, dezesseis patentes, começando em "Prata I" e terminando em "Global Elite", cedida somente aos jogadores mais habilidosos internacionalmente.

São estas capacidades intrínsecas de motivar a ação, resolver problemas e potencializar aprendizagens nas mais diversas áreas do conhecimento e da vida dos indivíduos (Fardo, 2013), encontrados no processo de desenvolvimento de games. Analisando a mecânica do jogo identificam-se cinco elementos com grande potencial de aplicação na educação que são: personificação, regras, objetivos, pontos e recompensas, detalhados na sequência.

\section{Relatando a experiência: gamificação como metodologia na disciplina de robótica}

As experiências relatadas foram realizadas com alunos do ensino superior. O relato do professor norte-americano Lee Sheldon (2012), na obra Multiplayer Classroom: Designing Coursework as a Game, explica como foi usada a lógica dos games ao lecionar em uma disciplina de Game Design (que tem por objetivo estudar como funciona a criação de games) em uma Instituição de Ensino Superior. Na educação básica é exemplo o trabalho desenvolvido por Hirano (2015), explica o uso de gamificação no ensino de Programação para Crianças, através de estudo comparando o desempenho de seis turmas com as quais empregou gamificação na metodologia e outra seis não. Com base nos 
resultados foi possível constatar um aumento no engajamento dos alunos $\mathrm{e}$ consequentemente, melhora no desempenho acadêmico nas turmas que tiveram ensino gamificado. Outro efeito observado nestas turmas foi que o número de faltas às aulas foi reduziu.

As pesquisas apresentadas demonstram o emprego da gamificação no processo educacional de adultos e crianças para o ensino de diferentes áreas. Na sequência relatase a experiência da gamificação aplicada ao ensino da Computação, através da Robótica na Escola de Educação Básica Educar-se, escola de aplicação da Universidade de Santa Cruz do Sul - UNISC. O ensino de Computação, através da robótica na educação básica, pode ser visto como um grande avanço, contudo, tão importante quanto promover o ensino dessa área é empregar novas metodologias. Buscando uma forma de trabalho coerente com a linguagem dos Nativos Digitais, essa experiência foi desenvolvida na disciplina de Robótica, ministrada por professor licenciando em computação. A atividade envolveu quatro turmas. Três turmas eram compostas por alunos do terceiro ao quinto ano e uma turma com alunos do sexto ao oitavo ano, totalizando, trinta e três alunos. Os resultados foram constatados a partir da comparação entre os dois primeiros trimestres do ano de 2016, em que não foi utilizada gamificação na metodologia, com o terceiro trimestre, em que a gamificação foi empregada e denominada "Temporada de Jogos".

Para as aulas de Robótica são utilizados kits de LEGO Mindstorms, modelo EV3, que permitem a programação com ferramenta visual. O uso de ferramentas visuais de programação reduz o gasto de tempo no aprendizado de uma nova linguagem, liberando mais tempo para resolução de problemas. Em um ambiente tradicional, os alunos recebem situações-problemas, o professor media a resolução e os alunos implementam e testam com o auxílio do robô. Ao final do processo o professor verifica a prática, fazendo as devidas considerações e observações. A metodologia utilizou a gamificação, retirando a figura do professor do centro do processo, oportunizando ao aluno ser membro ativo. $\mathrm{Na}$ prática, os elementos trazidos para o contexto escolar durante o processo de gamificação enfatizaram:

Personificação: Cada kit de robótica utilizado permite até quatro estudantes trabalhando juntos. O time é formado por um "engenheiro" (integrante responsável por montar a estrutura mecânica, motores, e finalizar a montagem do robô), um "eletrônico" (responsável por fazer a calibragem dos sensores, verificação das pilhas, baterias e barramentos), um "programador" (encarregado de programar o robô) e um "líder" (que representa o time na apresentação da tarefa, participa auxiliando e verificando o trabalho dos demais). Ao exemplo dos jogos multiplayer, cada aluno pode escolher o grupo e sua função nele, para desempenhar o cargo em que melhor se identifica. É importante lembrar que se deve usar a linguagem dos Nativos Digitais. Enquanto a palavra "grupo" ou "equipe" é normalmente usada para designar um conjunto de pessoas que se aplicam a uma tarefa ou trabalho, como no ensino tradicional, a palavra "time" é usada para designar um conjunto de indivíduos associados numa ação comum, com vista a determinado fim, um objetivo em comum, para o qual o trabalho de cada um converge. A figura 1 apresenta um time: 


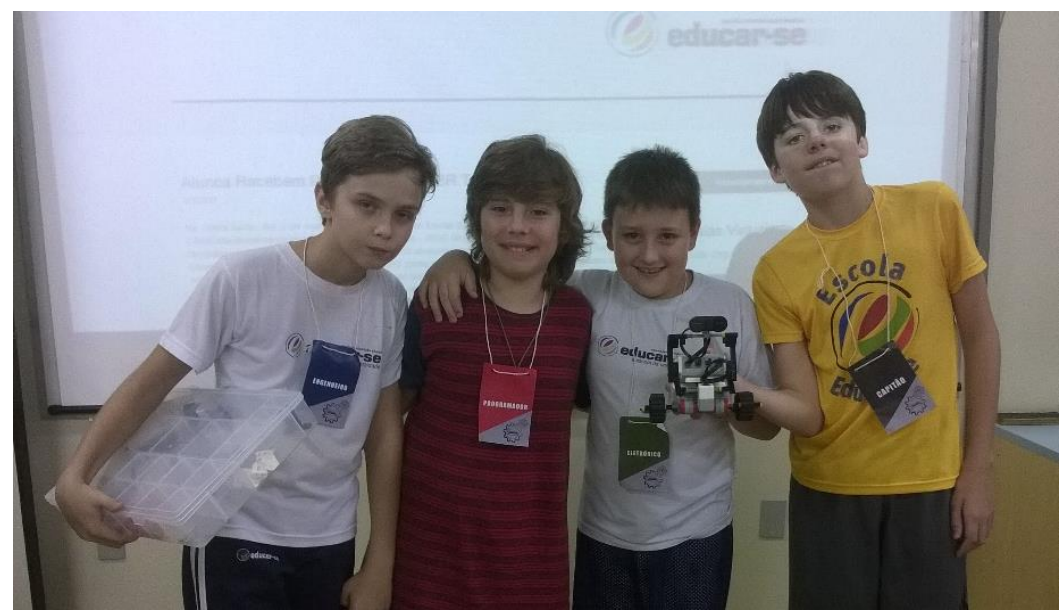

Figura 1. Composição de um time com os quatro integrantes/personagens

A atribuição de funções ou cargos aos integrantes do grupo soluciona um problema comum na disciplina de robótica: Como organizar para que quatro estudantes trabalhem simultaneamente com um único robô, sem deixar nenhum integrante sem atividade? Outro problema decorrente é como otimizar o tempo de trabalho, uma vez que, montar e programar robôs demandam de mais tempo do que há em uma aula. Com a divisão clara de tarefas, cada estudante assume um personagem em seu time e desempenha sua atribuição, permitindo paralelismo das atividades, otimizando o tempo disponível por atividade.

Regras: Seguindo a analogia dos jogos, regras que orientam a resolução das tarefas, pontuações e os critérios de avaliação devem estar bem definidos e claros para todos. São as regras que irão orientar a organização do trabalho de cada um no time. Toda nova tarefa dada é disponibilizada online em formato de texto, com o objetivo explicado claramente, os critérios de avaliação, bem como o valor em pontos de cada parte da tarefa. As tarefas no contexto do ensino da Computação são sempre objetivas e requerem a resolução de um problema e sua implementação com o auxílio do kit de robótica.

Objetivos: Assim como as regras, os objetivos devem estar claros e bem entendidos pelo time. O objetivo de cada tarefa é o foco para o qual todo o trabalho converge. Caso uma determinada tarefa seja muito ampla ou complexa, deve ser dividida em partes menores. Durante o período do ano em que o trabalho foi conduzido, o objetivo geral de cada time é somar o maior número de pontos. Os objetivos podem ser adaptados em função das habilidades que o professor espera que os alunos desenvolvam. No caso das turmas em questão, além de desenvolver o pensamento computacional, buscou-se desenvolver o trabalho em equipe, responsabilidade, autodesenvolvimento e organização. A figura 2 apresenta um exemplo de uma tarefa dada. Na tarefa o grupo precisou decompor o problema ao observar o padrão de repetição de movimentos para liberar as vítimas presas. Cada quadro da grade é representado por um espaço de $30 \mathrm{~cm}$ x $30 \mathrm{~cm}$. Outro aspecto interessante é que tudo pode valer pontos, mas necessita estar descrito nas regras. Pode-se atribuir uma parcela da pontuação para atividades como colocar as baterias a carregar após a aula e guardar o material adequadamente, incentivando bons hábitos. Na figura 2 é possível verificar o formato de uma das tarefas dadas, que contempla essas situações: 

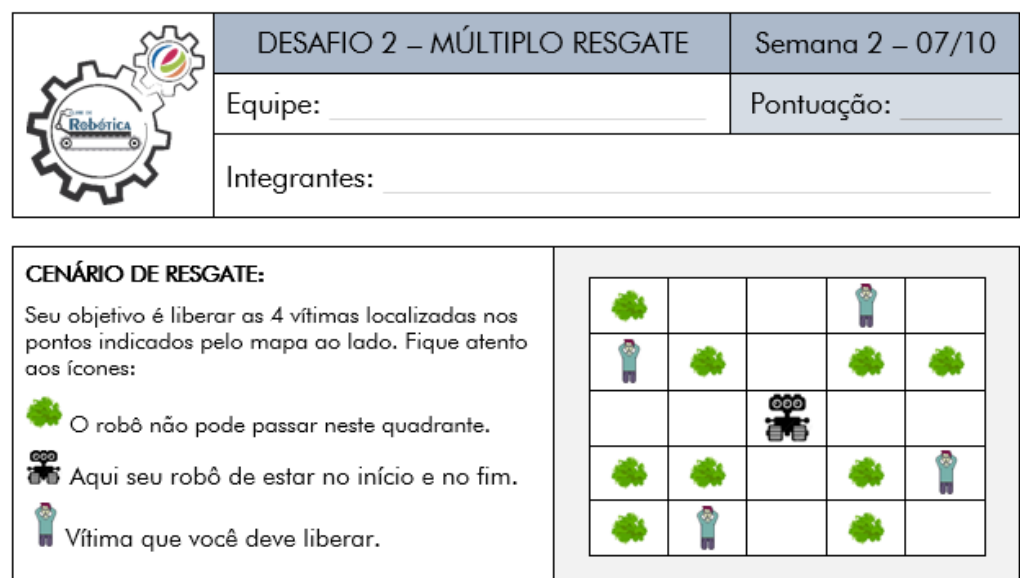

\begin{tabular}{|l|l|}
\hline AÇÃO: & VALOR: \\
É hora de montar e programar! & $\begin{array}{l}\text { Resolver a tarefa: } 8 \text { pontos; } \\
\text { Organizar e guardar o material: } 2 \text { pontos; }\end{array}$ \\
\hline
\end{tabular}

Figura 2. Exemplo de tarefa entregue impressa para cada time

Pontuação: Após a realização de cada tarefa, o time recebe imediatamente a sua pontuação, e a mesma é lançada em uma planilha do Microsoft Office Excel, no OneDrive, incorporada à página web do professor. $\mathrm{O}$ uso de planilhas eletrônicas em nuvem permite a atualização dos dados em tempo real, garantindo o feedback instantâneo ao time. Ao visualizar a pontuação obtida logo após concluir a tarefa, o time pode analisar e discutir as falhas e refletir sobre mudanças necessárias (técnicas ou organizacionais). Assim como nos games online, a pontuação é incremental e permite quantificar o avanço do time. Este instrumento foi denominado "Robotômetro" e encontra-se incorporado à página web disponível em http://robotica.kody.mobi.

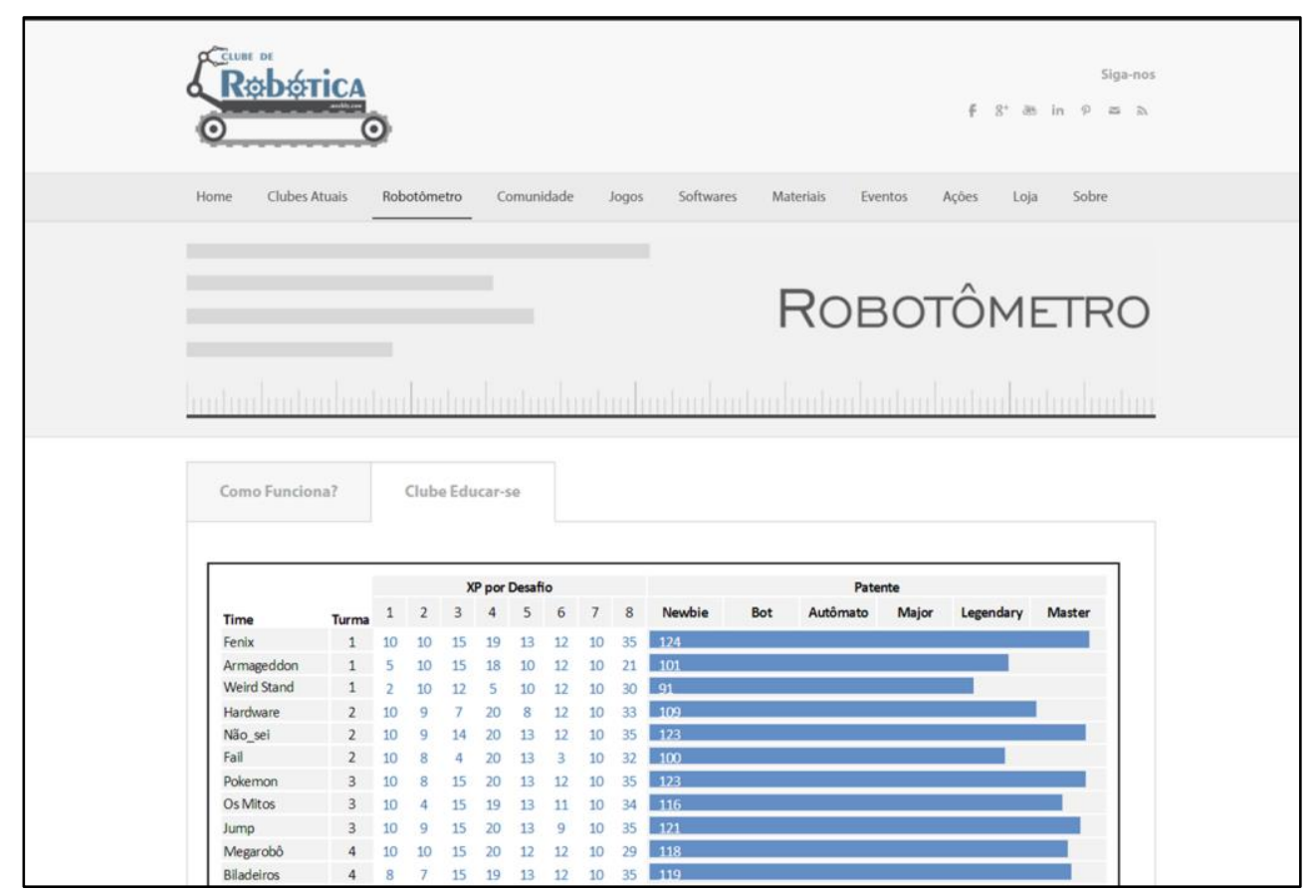

Figure 3. Tela da página do "robotômetro" no site do clube de robótica 
Recompensa: O "robotômetro" mantem o registro incremental da pontuação de cada time, discriminada por tarefa. A pontuação individual de cada aluno é registrada na planilha, mas não é publicada, sendo visível somente ao professor. A soma das pontuações de cada aluno que integra um time acresce à pontuação do time. A partir desse momento a pontuação é disponibilizada na página web. O nível do time é indicado por seis patentes: newbie, bot, autômato, major, legendary e master. Essa denominação emprega termos inspirados na ficção científica, robótica e jogos multiplayers.

\section{Os Resultados Alcançados}

Através da experiência, foi possível observar e comparar o desempenho dos estudantes na disciplina de robótica. Durante a "Temporada de Jogos" os estudantes mantiveram-se mais engajados e unidos dentro dos times, mostraram mais dedicação e comprometimento. Com base na melhora significativa do rendimento das quatros turmas foi possível constatar que o feedback na forma como foi apresentado é um elemento com grande potencial para incentivar a busca ao aperfeiçoamento e revisão das tarefas. Vale ressaltar que neste estudo a lógica dos games foi aplicada na disciplina de robótica, mas pode ser adaptada para qualquer disciplina ou conteúdo, independentemente do nível de ensino, como nos relatos citados.

Para auxiliar na avaliação da metodologia, foi realizada uma pesquisa através de formulário web anônimo, com quatro questões sobre o período destas atividades, durante a "Temporada de Jogos". Foi solicitado que considerassem apenas comparar este período de estudo com os meses anteriores da disciplina. $O$ formulário foi preenchido integralmente por 21 estudantes, sendo estes, 7 das séries finais, e 14 entre o $3^{\circ}$ e $5^{\circ}$ ano das séries iniciais. Quando questionados, 76,2\% acreditam que se dedicaram mais, e $57,1 \%$ procuraram revisar ou refazer suas tarefas antes de entregar, demostrando um aumento significativo no interesse pelo estudo. Também $76,2 \%$ acreditam que aprenderam mais durante este período de tempo, do que nos meses anteriores. Outros $19 \%$ acreditam que o método não interferiu na aprendizagem e 4,5\% consideram que não foi uma experiência positiva. Além da aprendizagem, os estudantes foram questionados sobre habilidades sociais como organização, trabalho em grupo, divisão de tarefas. Do total, $61,9 \%$ avaliaram ter melhorado a atuação no grupo. Nenhum estudante declarou ter sido prejudicado em termos de organização e trabalho em grupo durante a "Temporada de Jogos".

Analisando as respostas por nível de ensino conclui-se que a gamificação afetou diferentemente cada nível. Enquanto 93\% dos estudantes das séries iniciais dedicaram-se mais na resolução das tarefas, $57 \%$ dos alunos das séries finais acreditam que a metodologia não influenciou na sua dedicação. Por outro lado, $71 \%$ destes declararam revisar as tarefas antes de entregar, hábito que não possuíam, enquanto apenas $50 \%$ dos estudantes dos anos iniciais declararam o mesmo. Com relação à aprendizagem, $79 \% \mathrm{e}$ $72 \%$ das séries iniciais e finais, respectivamente, concordam que aprenderam mais durante a gamificação da disciplina. Relativo ao trabalho em equipe, $64 \%$ e $57 \%$ dos alunos das séries iniciais e finais responderam que trabalharam melhor em conjunto durante a gamificação. A figura 4 apresenta as a quantificação das respostas dada ao questionário: 


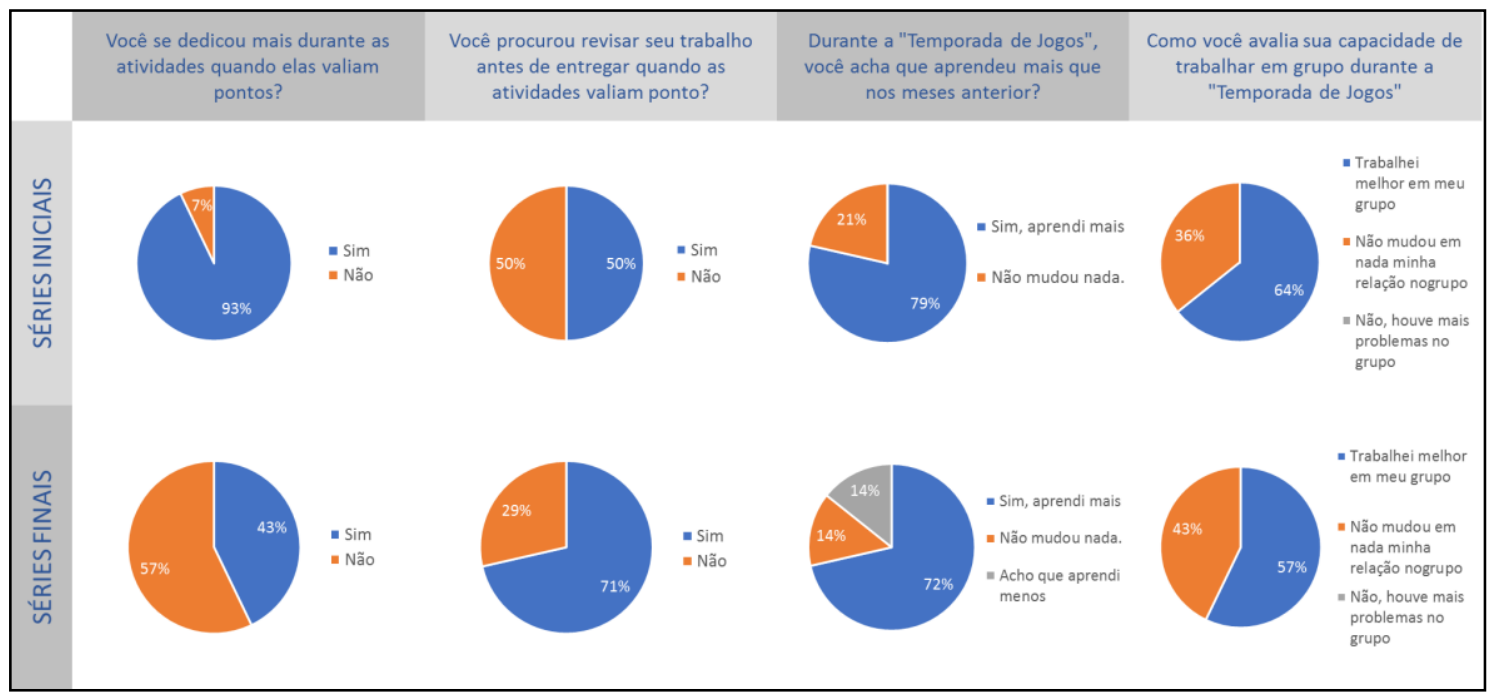

Figure 4. Gráfico com respostas da sondagem organizado por nível

\section{Conclusão}

Através da metodologia utilizada que valeu-se da gamificação no ensino de robótica foi possível constatar uma melhora significativa no desempenho das turmas. No que se refere à aprendizagem, incentivou a dedicação e a revisão das tarefas e a busca constante do conhecimento. A disciplina de robótica contribuiu efetivamente para a introdução de conteúdos da Computação. Promoveu também o engajamento entre os integrantes, a cooperação e o paralelismo das atividades. A proposta de utilização da gamificação para disciplina facultativa de robótica mostrou-se excelente junto à metodologia para o ensino de Computação e absolutamente coerente com a linguagem dos Nativos Digitais.

\section{Referências}

BARBOSA, L. S., Fernandes, T. C., and Campos, A. M. (2011). Takkou: Uma ferramenta proposta ao ensino de algoritmos. In Anais do CSBC/XIX WEI.

BATTISTELlA, Paulo. Wangenheim, C. G. V. (2016). Caracterização do Público-Alvo de Jogos Educacionais na área da Computação. In Anais do CSBC/XXIV WEI.

BRENNER, Wagner. Austrália classifica geografia e história como facultativas e acrescenta aulas de programação. Updateordie. Disponível em: http://www.updateordie.com/2015/09/22/australia-tirageografia-e-historia-dasescolas-em-favor-de-aulas-de-programacao. Acesso em Junho de 2015.

COLLAS. Aurélie. L'école se prépare à enseigner le code informatique. LEMONDE, julho de 2016. Disponível em: http://www.lemonde.fr/education/article/2016/06/06/1ecole-se-prepare-a-enseigner-lecode-informatique_4938182_1473685.html. Acesso em Julho de 2016.

CORREIA, A. L. et. al. (2015). Uso de avaliação por pares em disciplinas introdutórias de programação. In Anais do CSBC/XXIII WEI. 
CSTeachers. Csta k-12 computer science standards. Disponível em: https://www.csteachers.org. Acesso em julho de 2016. CRAWFORD, Cris. The Art of Computer Game Design. Versão eletrônica autorizada para acesso público da obra publicada em 1982. Disponível em http://wwwrohan.sdsu.edu/ stewart/cs583/ACGD_ArtComputerGameDesign_ChrisCrawford_1 982.pdf. Acesso em 08 de março de 2017.

FARDO, Marcelo Luiz. A Gamificação Como Estratégia Pedagógica: Estudo De Elementos Dos Games Aplicados Em Processos De Ensino E Aprendizagem, 2013.

HIRANO, Fabio Takashi. O Uso de Gamification no ensino de Programação para Crianças: um estudo de caso. 2015. Disponível em: https://linux.ime.usp.br/ fabioh/mac499/monografia.pdf. Acesso em 7 de março de 2017

MATTAR, João. Games em educação: como os nativos digitais aprendem. São Paulo: Pearson Prentice Hall, 2010. 181 p.

MASSA, S. Monica. (2015). A formação didático-pedagógica do docente da área de computação: um estudo de caso em uma Universidade Brasileira. In: Anais do XXIII WEI. SBC.

RIBEIRO, Leila. (2013) Painel sobre "O Pensamento Computacional no Ensino Fundamental e Médio" realizado em outubro de 2013 no II Workshop-Escola de Informática Teórica (WEIT). Instituto de Informática / UFRGS

SHELDON, Lee. The Multiplayer Classroom: Designing Coursework as a Game. Boston, MA: Cengage Learning, 2012

SCHMUNDT, Hilmar. Reading, writing, algorithms should it classes be required?, Spiegel online, 2013. Disponível em: http://www.spiegel.de/international/germany/experts-in-germany-dividedoncomputer-science-in-school-curriculum-a-899979.html. Acesso em junho de 2016. 